\section{RAF reunion}

I would be most grateful if you could kindly publish the enclosed names and 1959 graduation photo of the RAF hygienists.

We are hoping to organise a reunion event - even $70+$ year old ladies have not forgotten how to party! (We'll even send you the pictures when we meet up.)

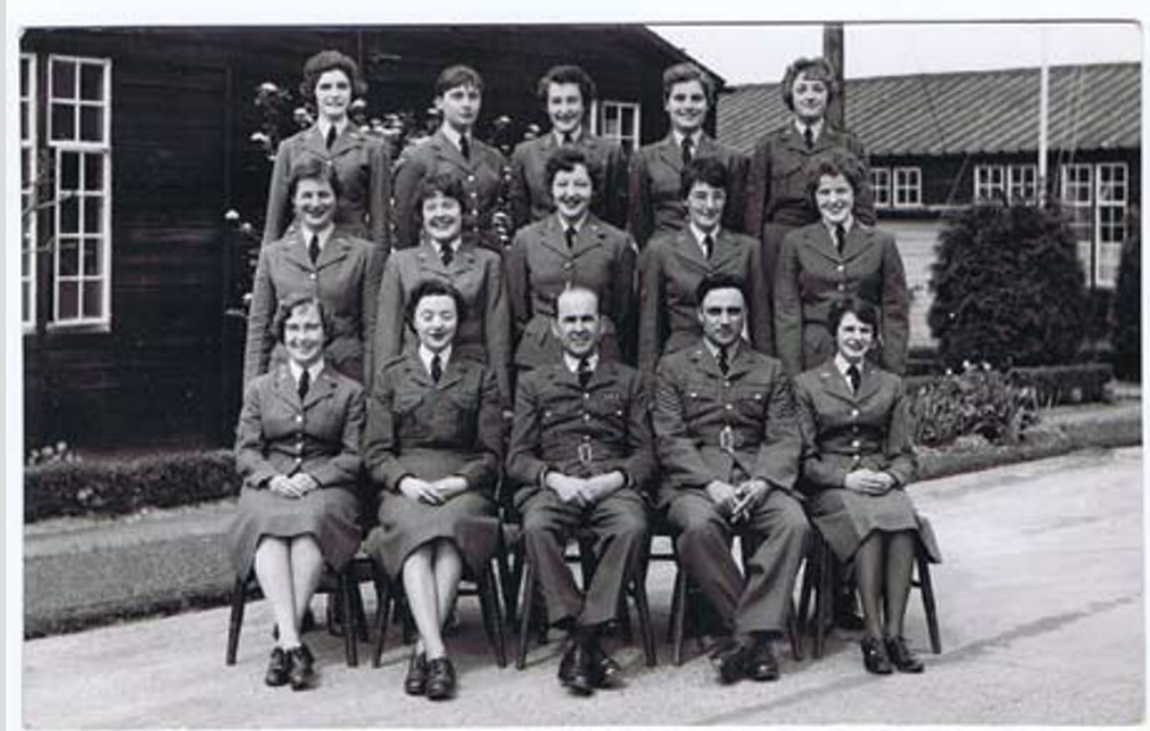

Dental hygienist course 22 October 1959. Front row Brenda Willis (left), Marian Magdaburg (right): middle row I to r Madge Oldham, Vera Hatzfeld, Alison Halford, Fiona Fleming, Lucy Edwards; back row I to r Edna Birch, (?), Brenda O'Neill, Jan Corless, Sylvia McKie.

\section{Chuffed}

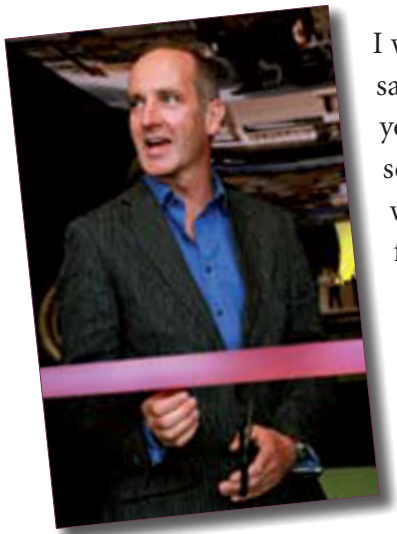

I would just like to say a huge thank you to Vital for sending me the winning tickets for the Grand Designs Live competition. My husband and I went up on Sunday and we had a most enjoyable day out and spent far too much money! I was chuffed as I never win anything normally and it was a great surprise, especially as I had forgotten that I had entered the competition!

So thank you once again; I look forward to my next issue of Vital.

\section{Amanda Leogue \\ Dental Hygienist}

We'd love to hear from or about any of the graduates or their families.

Please telephone 01453882216 or email john@johneagles.wanadoo.co.uk.

Brenda Eagles (née Willis)

\section{Core CPD in Vital}

We are thinking about registering for Vital online verifiable CPD. Could you please let us know if the eight hours will include the core subjects?

\section{Leona Thompson}

By email

Ed's response: I receive numerous emails like this so I thought that I would reply on the $V$-mail page this issue. Registered DCPs need to complete 150 hours of CPD per five year cycle, 50 hours of which must be verifiable. Verifiable $C P D$ is $C P D$ that can be verified by a third party. With Vital CPD your verifiable CPD will be verified by a certificate. Each certificate represents one hour of $C P D$.

The GDC recommends that the whole dental team covers $C P D$ in the following core areas over the five year cycle:

- At least ten hours of CPD in medical emergencies

- At least five hours of CPD in disinfection and decontamination

- At least five hours of CPD in radiography and radiation protection.

All those who work in a clinical or laboratory environment are advised to also carry out CPD (verifiable or non-verifiable) in legal and ethical issues and in complaints handling. Vital CPD provides eight hours of verifiable CPD per year either via our website or through the post. This is equivalent to 40 hours of verifiable CPD over five years. Over these 40 hours of CPD the core subjects will be covered.

Over the last year the following verifiable CPD was included in Vital: decontamination (2 hours), complaints (1 hour), clinical governance (1 hour), radiography (1 hour), medical emergencies (1 hour), oral health education (1 hour) and ethics (1 hour).

You can also include reading other Vital articles in your non-verifiable (general) CPD. Just keep a record of which articles you have read and how long you spent reading them. You can even look at past issues of Vital on the online archive, which goes back to 2003. See http:// www.nature.com/vital/archive/index.html.

Claire Willetts, Halesowen Hilary Samways, Sheffield Jacqui Frye, Hounslow Rachel Hawker, Cheltenham Kim Howard, Tongham Amanda Leogue, Worthing Sally Hart, Barrow-in-Furness Sue Smith, Bushey

Elian Lorrae Jones-Southgate, Aberystwyth Tessa Wright, Winchester 